\title{
Long-term expression of murine activated factor VII is safe, but elevated levels cause premature mortality
}

\author{
Majed N. Aljamali, ${ }^{1}$ Paris Margaritis, ${ }^{1}$ Alexander Schlachterman,, ${ }^{1}$ Shing Jen Tai, ${ }^{1}$ \\ Elise Roy, ${ }^{1}$ Ralph Bunte, ${ }^{2}$ Rodney M. Camire, ${ }^{1}$ and Katherine A. High ${ }^{1,3}$ \\ 1Division of Hematology, The Children's Hospital of Philadelphia, Philadelphia, Pennsylvania, USA. \\ 2Department of Pathology, School of Veterinary Medicine, University of Pennsylvania, Philadelphia, Pennsylvania, USA. \\ ${ }^{3}$ Howard Hughes Medical Institute, The Children's Hospital of Philadelphia, Philadelphia, Pennsylvania, USA.
}

\begin{abstract}
Intravenous infusion of recombinant human activated Factor VII (FVIIa) has been used for over a decade in the successful management of bleeding episodes in patients with inhibitory antibodies to Factor VIII or Factor IX. Previously, we showed that expression of murine FVIIa (mFVIIa) from an adeno-associated viral (AAV) vector corrected abnormal hemostatic parameters in hemophilia B mice. To pursue this as a therapeutic approach, we sought to define safe and effective levels of FVIIa for continuous expression. In mice transgenic for mFVIIa or injected with AAV-mFVIIa, we analyzed survival, expression levels, in vitro and in vivo coagulation tests, and histopathology for up to 16 months after birth/mFVIIa expression. We found that continuous expression of mFVIIa at levels at or below $1.5 \mu \mathrm{g} / \mathrm{ml}$ was safe, effective, and compatible with a normal lifespan. However, expression levels of $2 \mu \mathrm{g} / \mathrm{ml}$ or higher were associated with thrombosis and early mortality, with pathologic findings in the heart and lungs that were rescued in a low-factor X (low-FX) mouse background, suggesting a FX-mediated effect. The findings from these mouse models of continuous FVIIa expression have implications for the development of a safe gene transfer approach for hemophilia and are consistent with the possibility of thromboembolic risk of continuously elevated FVIIa levels.
\end{abstract}

\section{Introduction}

Hemophilia results from mutations in either of 2 genes, $F 8$ or F9, which encode proteins in the intrinsic pathway of coagulation. The current approach to therapy is intravenous infusion of the missing or defective coagulation factor, but work by Hedner and colleagues has established that infusion of recombinant human activated Factor VII (rhFVIIa; NovoSeven), a critical protein in the extrinsic pathway, can restore hemostasis through rhFVIIa-catalyzed generation of thrombin in patients with antibodies to Factor VIII (FVIII) or Factor IX (FIX) (1-3). Based on the current understanding of the coagulation cascade, all patients with hemophilia could conceivably be treated with rhFVIIa, a protein to which all such patients have immunological tolerance. This would simplify hemophilia management to a single product, but the high cost, short half-life, and ongoing concerns about risk of thrombosis with rhFVIIa (4) have limited this approach.

In previous studies in hemophilic mice, we showed that a gene transfer approach could circumvent the issue of short half-life, because activated FVII can be continuously expressed from a donated gene introduced into the liver via an adeno-associated viral (AAV) vector (5). The engineered FVII construct contained a nucleotide sequence encoding RKRRKR (referred to herein as 2RKR) inserted between Arg152 and Ile153 - the normal site of cleavage - to allow secretion of activated FVII. Expression of such an engineered

Nonstandard abbreviations used: -a, activated; AAV, adeno-associated viral (virus); aPTT, activated partial thromboplastin time; FIX, Factor IX; FVII, Factor VII; FVIII, Factor VIII; FX, Factor X; h-, human; HB, hemophilia B; m-, murine; p-, plasmid; PT, prothrombin time; rh-, recombinant human; TAT, thrombin-antithrombin; TF, tissue factor; TTR, transthyretin.

Conflict of interest: R.M. Camire receives research support from Novo Nordisk. Citation for this article: J. Clin. Invest. 118:1825-1834 (2008). doi:10.1172/JCI32878
FVIIa improved hemostasis in hemophilia B (HB) mice following $\mathrm{AAV}$-mediated gene transfer. To further pursue vector-mediated expression of FVIIa as a possible therapeutic approach, we sought to define the range of FVIIa levels that restore hemostasis and are safe when expressed continuously. As an experimental approach, we generated transgenic mice expressing a range of levels of murine FVIIa (mFVIIa), detected using an assay specific for mFVIIa that shows minimal cross-reactivity to mFVII. We categorized mice from different transgenic lines as low and high expressers based on plasma levels of mFVIIa and crossed them to HB mice. We carried out similar analyses of mice injected with an $A A V$ vector expressing mFVIIa. We found that when mFVIIa was continuously expressed in transgenic mice, even low levels were sufficient to improve hemostasis in a mouse model of hemophilia; moreover, continuous expression of mFVIIa at levels up to $1,500 \mathrm{ng} / \mathrm{ml}(30 \mathrm{nM})$ was compatible with a normal lifespan in mice. Identical findings were observed in mice injected with doses of AAV-mFVIIa adequate to generate circulating mFVIIa levels of $300-800 \mathrm{ng} / \mathrm{ml}(6-16 \mathrm{nM})$, and overexpression of mFVIIa at levels greater than 2,000 ng/ml (40 nM) caused early mortality in both normal and hemophilic mice, with pathology predominantly in heart and lungs. We also demonstrated that crossing mFVIIa-overexpressing mice into a newly generated low-factor X (low-FX) mouse model (6) resulted in restoration of normal longevity and decreased thrombin generation, which indicates that the shortened lifespan of the high expressers is mediated through the coagulation cascade rather than another mFVIIamediated signaling event. These results establish ranges for hemostatic efficacy of continuously expressed mFVIIa in a mouse model and also define upper limits for safety for continuously expressed mFVIIa. They also demonstrate an association between continuously elevated levels of FVIIa and premature mortality. 

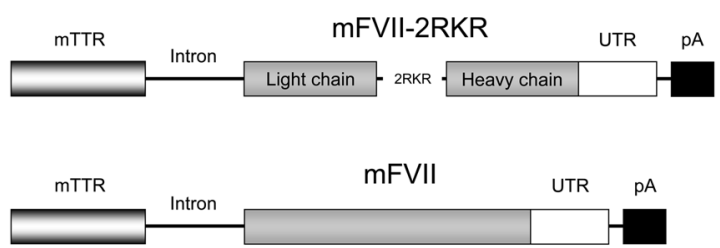

\section{Figure 1}

Transgenic construct for mFVIIa (mFVII-2RKR) and mFVII zymogen mice. The mFVIIa/mFVII cDNA is under control of the mTTR promoter separated by a synthetic intron. A polyadenylation signal $(\mathrm{pA})$ from bovine growth hormone follows the $3^{\prime}$ untranslated region (UTR) for both cDNAs.

\section{Results}

Generation of transgenic mice expressing mFVIIa at a range of levels. Our initial studies using AAV vector-mediated FVIIa gene transfer demonstrated the efficacy of continuously expressed mFVIIa in effecting hemostasis in a murine model of hemophilia (5). As a next step, we sought to determine the minimum levels of mFVIIa required for efficacy and the maximum levels that would be safely tolerated. We chose to analyze the safety and efficacy of a range of circulating mFVIIa levels using both transgenic and $\mathrm{AAV}$-injected mice; compared with vector-treated mice, transgenic animals offer the advantages of decreased intragroup variation in mFVIIa levels among littermates, maintenance of similar levels of mFVIIa from one generation to the next, and no requirement for vector preparation and injection. For construction of the transgene, we used the mFVII cDNA (7) in order to ensure optimal interaction with murine tissue factor (TF), and we engineered the mFVII construct to allow secretion of activated mFVIIa by insertion of a nucleotide sequence encoding 2 RKR between Arg152 and Ile153, as previously described (5). A cDNA coding for a WT mFVII was also used to generate control animals expressing WT (zymogen) mFVII (Figure 1). In both constructs, expression was under the control of the murine transthyretin (TTR) promoter as previously described (8). Founders (14 of 160 [8.7\%] microinjected fertilized eggs for the mFVIIa constructs, 5 of 55 [9\%] for the mFVII zymogen constructs) were identified both by genotyping and, in the case of the mFVIIa transgenic mice, by shortening of the prothrombin time (PT), with $100 \%$ concordance between the 2 assays in the mFVIIa mice. We analyzed a total of 12 independent founder lines carrying the mFVIIa transgene and 5 lines carrying the mFVII (zymogen) transgene. Founder lines are referred to herein as F0; subsequent generations of offspring from crosses into C57BL/6 pure background are denoted N1-N4. As expected from the transgene positional effects, the transgenic founder lines expressed a range of mFVII or mFVIIa levels from 500 to $5,500 \mathrm{ng} / \mathrm{ml}$, as measured by total antigen ELISA and by PT (Table 1). However, mFVIIa levels were approximately equivalent from one generation to the next $(\mathrm{F} 0,3,730 \pm 715 \mathrm{ng} / \mathrm{ml} ; \mathrm{N} 1,3,540 \pm 1,300 \mathrm{ng} / \mathrm{ml}$; $\mathrm{N} 2,3,110 \pm 955 \mathrm{ng} / \mathrm{ml} ; P=0.232)$. An active site inhibitor-based ELISA was also developed to determine levels of mFVIIa in the transgenic founder lines; this showed minimal crossreactivity to mFVII zymogen (Table 1) and was used for the remainder of the study. Although overexpression of a procoagulant factor most likely results in some degree of inactivation by circulating serpins, the antigen assay used here with an active site inhibitor enabled us to define the levels and the effect of free, uninhib- ited mFVIIa. For additional analyses, mFVIIa transgenic animals were grouped arbitrarily into low expressers (500-1,500 ng/ml mFVIIa as assessed by active site inhibitor ELISA) or high expressers $(2,000-5,500 \mathrm{ng} / \mathrm{ml} \mathrm{mFVIIa})$. For both groups, transgenic mice were born in expected proportions $(50 \%$ in cross with $\mathrm{C} 57 \mathrm{BL} / 6 \mathrm{WT}$ or $\mathrm{HB}$ ), and nontransgenic littermates were used as controls in all assays.

Hemostasis is improved in mice with hemophilia A or HB after crossing to mFVII transgenic mice or administering $A A V$-mFVIIa. To assess the efficacy of continuously expressed mFVIIa in restoring hemostasis in hemophilic mice, we crossed carrier hemophilic (both A and B) C57BL/ 6 female mice to mFVIIa transgenic male mice and assessed mFVIIa levels, PT, activated partial thromboplastin time (aPTT), and thrombin-antithrombin (TAT) complex levels and performed assays of in vivo clot formation (blood loss after tail clip, real-time clot formation in cremaster muscle arterioles after laser injury, and occlusion of carotid artery after $\mathrm{FeCl}_{3}$ injury) in transgenic and nontransgenic littermates. As expected, the nontransgenic littermates, both WT and hemophilic, showed baseline levels of mFVIIa in the circulation $(-150 \mathrm{ng} / \mathrm{ml})$, while average mFVIIa levels in the HB-low-mFVIIa transgenic mice were approximately $1,000 \mathrm{ng} / \mathrm{ml}$ and in the HB-high-mFVIIa transgenic mice about $3,000 \mathrm{ng} / \mathrm{ml}$ (Figure 2A). PT progressively shortened as circulating mFVIIa levels increased (Figure $2 \mathrm{~B}$ ). The aPTT was restored to the WT range in hemophilic mice expressing low-range mFVIIa $(P=0.6$ versus WT) and was reduced to shorter than normal values for the high expressers $(P<0.0001$ versus WT; Figure 2C). As a surrogate measure of thrombin generation, we measured the levels of TAT. HB mice expressing low and high levels of mFVIIa showed a dose-dependent increase in TAT levels $(P<0.05$, HB-low-mFVIIa versus HB-high-mFVIIa; Figure 2D). These data were further confirmed by shortening of clot formation times and increase in alpha angles on rotational thromboelastometry in citrated blood from HB mice with the mFVIIa transgene compared with nontransgenic HB littermates (data not shown). Similar results for in vitro clotting assays were obtained when mFVIIa transgenic mice were crossed with hemophilia A mice (data not shown). In contrast to HB-mFVIIa transgenic animals, HB mice transgenic for mFVII zymogen (expressing about $1,700 \mathrm{ng} / \mathrm{ml}$ total antigen and approximately $150 \mathrm{ng} / \mathrm{ml} \mathrm{mFVIIa)}$ showed a modest reduction in PT, no improvement in aPTT, and no increase in TAT levels (Figure 2). For comparison, another cohort of HB mice $(n=8)$ were injected via the portal vein with an AAV2 vector at a range of doses $\left(3 \times 10^{11}-1.2 \times 10^{12}\right.$ vector genomes/mouse $)$. This resulted in

Table 1

mFVII and mFVIla levels in transgenic founders or WT controls

$\begin{array}{lcccc}\text { Group } & \boldsymbol{n} & \begin{array}{c}\text { mFVII/FVIIa } \\ \text { total antigen } \\ \text { (ng/ml) }\end{array} & \begin{array}{c}\text { mFVIla antigen, } \\ \text { biotinylated inhibitor } \\ \text { ELISA }(\mathbf{n g} / \mathbf{m l})\end{array} & \text { PT (s) } \\ \text { High-mFVIla Tg } & 6 & 4,250 \pm 1,100 & 3,150 \pm 800 & 11.9 \pm 0.9 \\ \text { LoW-mFVIIa Tg } & 6 & 2,000 \pm 350 & 1,150 \pm 600 & 15.2 \pm 1.2 \\ \text { WTA } & 30 & 900 \pm 450 & 150 \pm 100 & 21.9 \pm 1.0 \\ \text { mFVII Tg } & 5 & 2,050 \pm 550 & 150 \pm 50 & 20.8 \pm 1.3 \\ \text { WTB } & 4 & 800 \pm 300 & 100 \pm 100 & 22.4 \pm 0.7\end{array}$

Values are mean $\pm 1 \mathrm{SD}$. A Littermates of $\mathrm{mFVIla}$ transgenic mice. BLittermates of mFVII transgenic mice. 

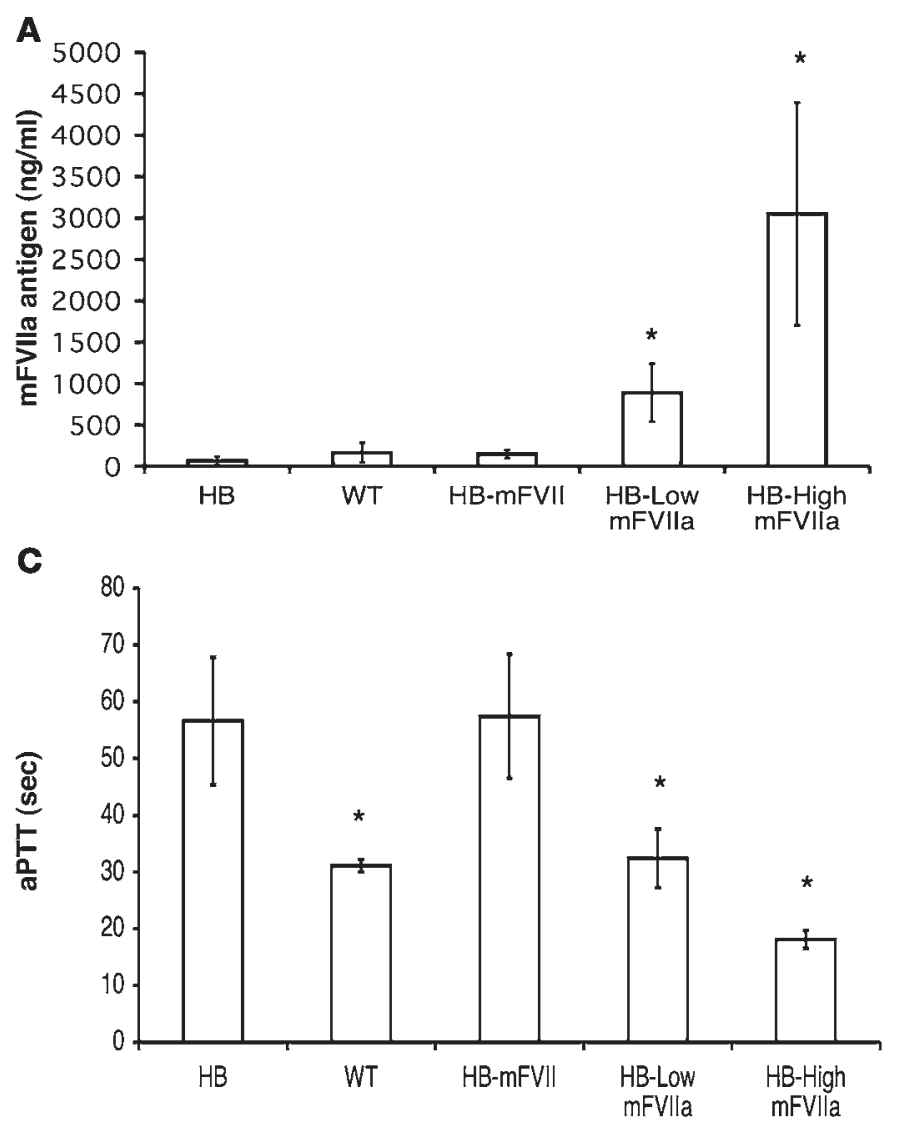

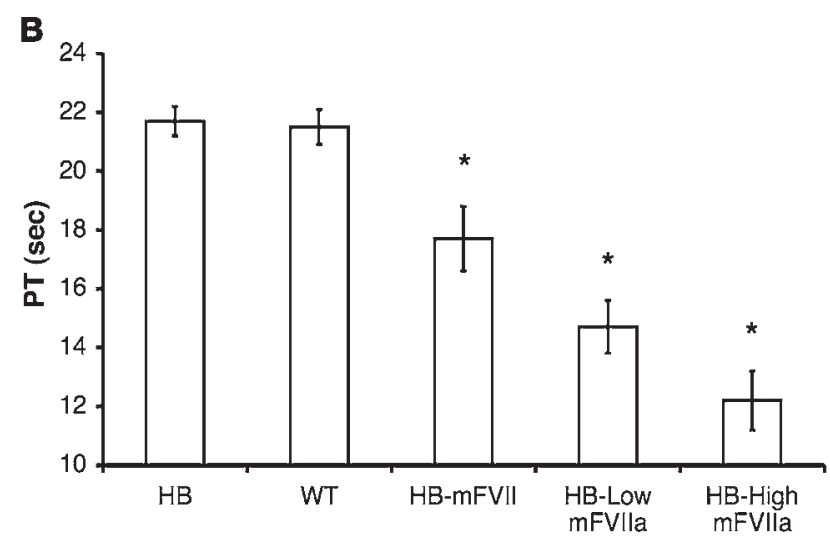

D

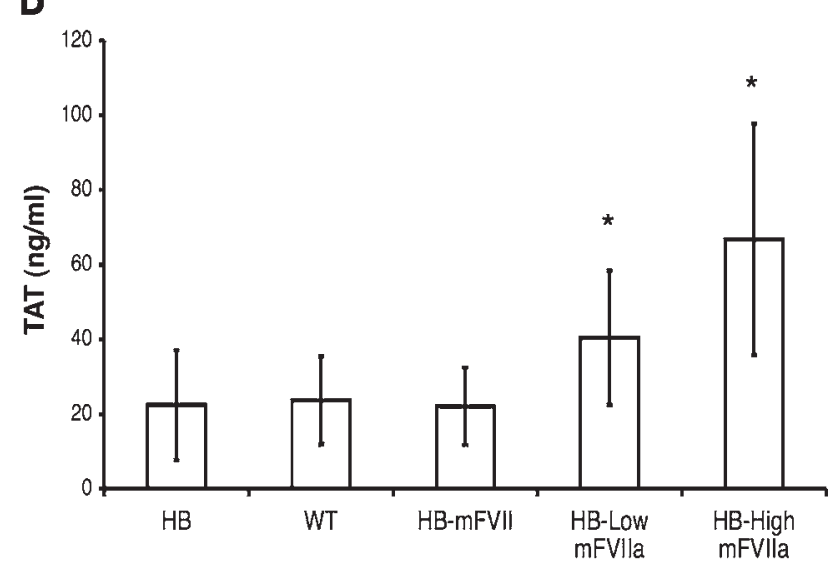

Figure 2

Efficacy of the mFVIla or the mFVII zymogen transgene in HB mice. (A) Plasma mFVIla levels (mFVII levels were measured by a separate antigen ELISA resulting in $\sim 1,700 \mathrm{ng} / \mathrm{ml})$, (B) PT, (C) aPTT, and (D) TAT levels in littermate HB $(n=21)$, WT $(n=21), \mathrm{HB}-\mathrm{mFVII}(n=4)$, HB-lowmFVIla $(n=10)$, and HB-high-mFVIla $(n=7)$ mice. ${ }^{*} P<0.05$ versus HB. Values are mean \pm 1 SD.

mFVIIa levels of $300-800 \mathrm{ng} / \mathrm{ml}$ (mean, $510 \mathrm{ng} / \mathrm{ml}$ ), which was adequate to reduce aPTT, PT, and blood loss following a tail-clip assay and to dramatically improve long-term survival (Table 2). Thus, the results obtained from the AAV-injected mice closely resemble those obtained from the transgenic mice.

Low levels of mFVIIa improve in vivo clot formation in the microcirculation of hemophilic mice, but not in the macrocirculation of mFVIIa transgenic mice. To further analyze the hemostatic efficacy of varying mFVIIa levels, we used assays that allowed us to assess clot formation in a living mouse. A tail-clip bleeding test, in which the tail was severed at a diameter of $3 \mathrm{~mm}$, was used to determine total blood loss during a 10 -minute time period, as measured by $\mathrm{OD}_{575 \mathrm{~nm}}$ of a saline solution into which the tail was submerged, following red blood cell lysis. Total blood loss and bleeding time were reduced in the HB-mFVIIa transgenic mice compared with hemophilic nontransgenic littermates $(P<0.05)$, although not to the normal levels seen in WT littermates (Figure $3 \mathrm{~A}$ and data not shown). In contrast to the in vitro coagulation assays (PT and aPTT), there was no difference in bleeding time parameters between HB-low-mFVIIa and HB-high-mFVIIa mice $(P=0.5$; data not shown). Hemophilic mice transgenic for mFVII zymogen showed no significant improvement in blood loss following tail clip compared with hemophilic nontransgenic littermates (data not shown).
In a second in vivo model, thrombus formation was assessed following a laser injury to a small arteriole (50 $\mu \mathrm{m}$ diameter) in the cremaster muscle by monitoring platelet accumulation at the site of injury (9). By assessing both kinetics of clot formation and the size of the formed thrombus, we determined that untreated HB littermates ( $n=2,14$ injury sites) failed to form clots even after the extended time period of 10 minutes. In contrast, both HB-low-mFVIIa and HB-high-mFVIIa mice $(n=3,24$ sites) displayed kinetics and clot volume indistinguishable from those of WT littermates ( $n=5,30$ sites; Figure $3 \mathrm{~B}$ ), which suggests that relatively modest levels of mFVIIa (mean $\sim 1,000 \mathrm{ng} / \mathrm{ml}$, or $20 \mathrm{nM}$, in low expressers) cause improved hemostasis in the microcirculation. This finding of efficacy at low-mFVIIa levels in the cremaster arteriole model is consistent with data we generated using an AAV-mFVIIa vector to correct hemostasis in hemophilic mice (Table 2). Finally, using a third in vivo test of thrombosis, the $\mathrm{FeCl}_{3}$-carotid artery injury model, we found no evidence of clot formation in either the high or the low expressers (Figure 3C).

Continuous expression of mFVIIa at less than $1,500 \mathrm{ng} / \mathrm{ml}$ is associated with normal life expectancy, but expression at more than 2,000 $\mathrm{ng} / \mathrm{ml}$ is associated with premature mortality. To assess the safety of continuous expression of mFVIIa, we determined survival in cohorts of mFVIIa transgenic, nonhemophilic mice as a function of circulat- 
Table 2

Efficacy and survival following hepatic administration of AAV2-mFVIla in HB mice

\begin{tabular}{|c|c|c|c|c|c|c|}
\hline Group & mFVIIa $(\mu \mathrm{g} / \mathrm{ml})$ & PT (s) & aPTT (s) & $0 D_{575 m^{A}}$ & Survival at $19 \mathrm{mo}$ & Clots $^{B}$ \\
\hline AAV2-mFVIIa & $\begin{array}{c}0.51 \pm 0.19 \mathrm{C}, \mathrm{D} \\
(n=11)\end{array}$ & $\begin{array}{c}27.9 \pm 2.3^{c} \\
(n=11)\end{array}$ & $\begin{array}{c}49.1 \pm 16.3^{c} \\
(n=11)\end{array}$ & $\begin{array}{c}0.7 \pm 0.5^{\mathrm{C}, \mathrm{D}} \\
(n=14)\end{array}$ & $\begin{array}{c}85 \% \mathrm{E} \\
(n=14)\end{array}$ & $\begin{array}{l}68 \text { of } 68^{C} \\
(n=10)\end{array}$ \\
\hline HB & $\begin{array}{c}0.16 \pm 0.07 \\
(n=3)\end{array}$ & $\begin{array}{c}31.3 \pm 3.5 \\
(n=3)\end{array}$ & $\begin{array}{c}66.3 \pm 9.7^{D} \\
(n=3)\end{array}$ & $\begin{array}{c}2.6 \pm 0.7^{D} \\
(n=13)\end{array}$ & $\begin{array}{c}45 \% \\
(n=11)\end{array}$ & $\begin{array}{l}0 \text { of } 30 \\
(n=5)\end{array}$ \\
\hline WT & $\begin{array}{c}0.13 \pm 0.11 \\
\quad(n=5)\end{array}$ & $\begin{array}{c}29.9 \pm 1.6 \\
(n=5)\end{array}$ & $\begin{array}{c}34.9 \pm 2.6 \\
(n=5)\end{array}$ & $\begin{array}{l}0.3 \pm 0.2 \\
(n=15)\end{array}$ & $\begin{array}{l}100 \% \\
(n=5)\end{array}$ & $\begin{array}{c}45 \text { of } 45 \\
(n=5)\end{array}$ \\
\hline
\end{tabular}

AAV2-mFVIIA was administered at $3 \times 10^{11}-1.2 \times 10^{12}$ vector genomes/mouse. Untreated HB and WT mice were used as controls. Values for mFVIla, PT,

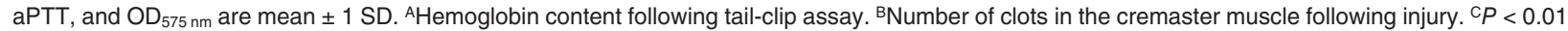
versus $H B$. ${ }^{D} P<0.01$ versus $W T$. $E P<0.05$ versus $H B$.

ing mFVIIa levels (Figure 4). Over a 16-month period of observation, survival in the low mFVIIa expressers was equivalent to that of nontransgenic WT littermates. Longer periods of observation, up to 24 months, showed the same result (data not shown), and these results are consistent with those obtained from AAV-injected mice (Table 2). However, for the high mFVIIa expressers, survival was reduced, with $50 \%$ of founders surviving at 16 months $(P<0.02$ versus WT; Figure 4). Results were similar when the high expressers were crossed to HB mice: FIX levels less than $1 \%$ did not protect against premature mortality (data not shown). Backcrossing into C57BL/ 6 mice further reduced survival, with typically $20 \%$ of pups dying in the first $72 \mathrm{~h}$ after birth. Even among those surviving the first $72 \mathrm{~h}$, lifespan was shortened compared with nontransgenic littermates, with $50 \%$ of $\mathrm{N} 1$ mice dead at 3 months $(P<0.0001$ versus WT) and $50 \%$ of N2 mice dead at 1 month $(P<0.0001$ versus WT; Figure 4). Mortality rates on backcrossing were similar for 3 separate high-mFVIIa founder lines. The cause of the progressively earlier mortality on backcrossing was investigated, but not found:

\section{Figure 3}

In vivo tests of coagulation. (A) Blood loss in mFVIIa transgenic HB mice expressing low (HB-Low mFVIla, $n=10$ ) or high (HB-High mFVIla, $n=8$ ) levels of mFVIla, compared with $\mathrm{HB}(n=20)$ and WT $(n=10)$ littermates. ${ }^{*} P<0.05$ versus HB. Values are mean \pm 1 SD. (B) Representative cremaster real-time thrombus formation in WT, HB, or HB-mFVIla (high and low expresser) mice. (C) $\mathrm{FeCl}_{3}$ carotid artery injury in WT, HB, or HB-mFVIIa (high and low expresser) mice. The single asterisk denotes the time at which the $\mathrm{FeCl}_{3}$ patch was applied; the double asterisk denotes vessel occlusion. Results are from 1 indicative mouse per group.
A

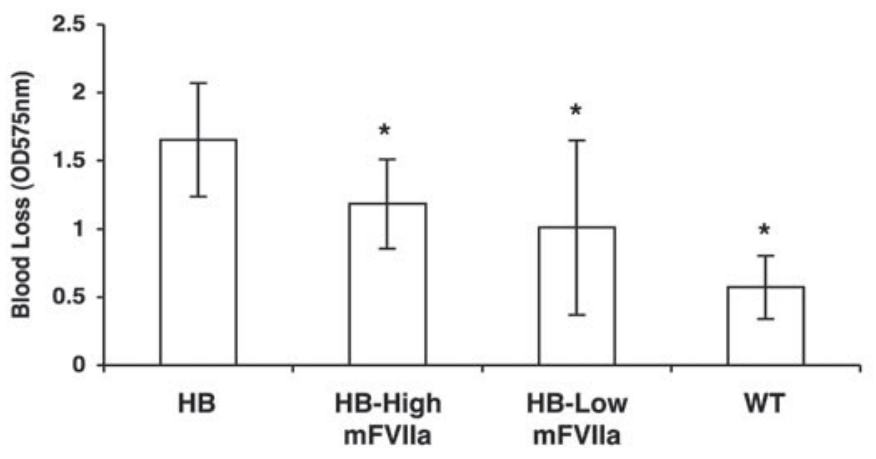

B
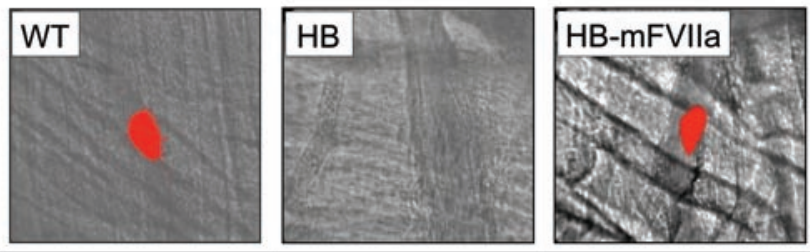

\begin{tabular}{|c|c|c|c|}
\hline Mice $(n)$ & 5 & 2 & 3 \\
\hline Sites injured & 30 & 14 & 24 \\
\hline $\begin{array}{c}\text { Number of } \\
\text { clots }(\%)\end{array}$ & $30(100)$ & $0(0)$ & $24(100)$ \\
\hline
\end{tabular}

C

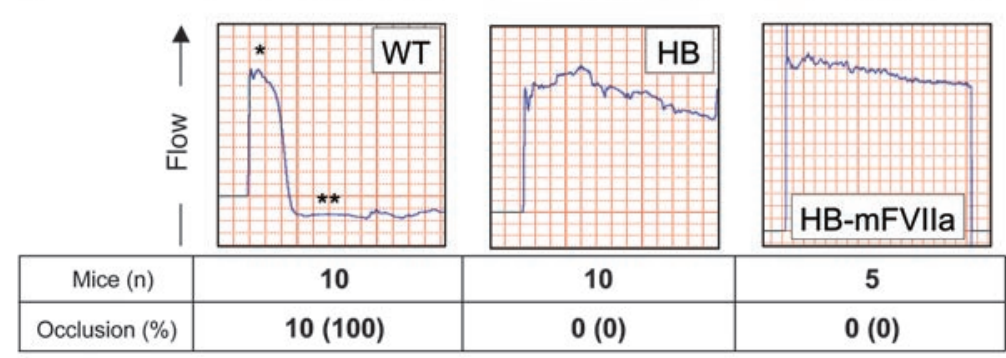




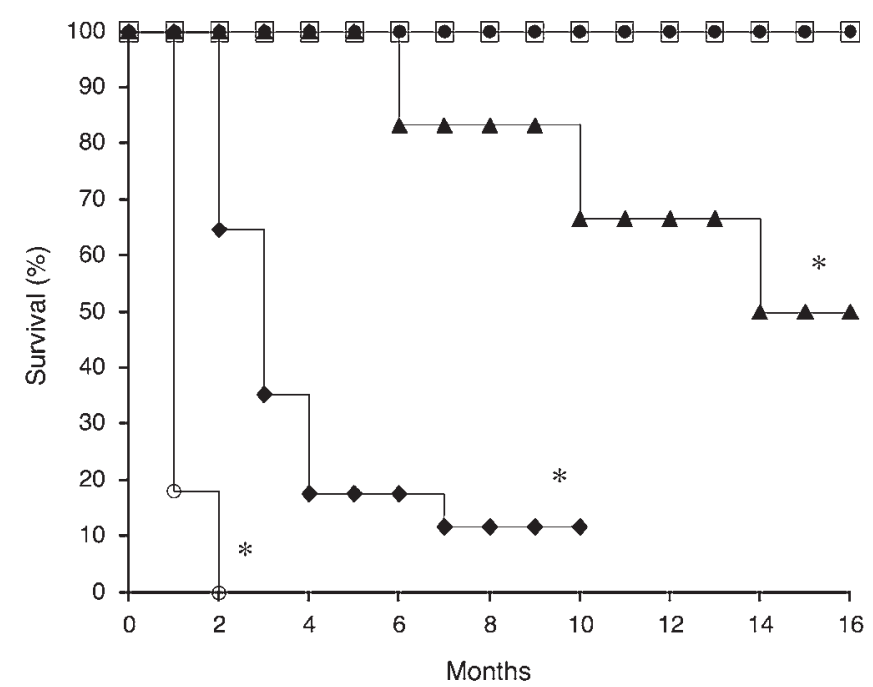

Figure 4

Expression of high mFVIla levels is associated with increased mortality after crossing the founder C57BL/6-SJL mice into C57BL/6 pure strain background. Kaplan-Meier survival plot of transgenic mFVIla mice with low or high levels of transgene expression compared with WT littermates. Curves for high mFVIla expressers exclude animals dying within $72 \mathrm{~h}$ of birth. Squares, WT $(n=10)$; filled circles, lowmFVIla N1-N4 $(n=25)$; triangles, high-mFVIla F0 $(n=6)$; diamonds, high-mFVIla N1 $(n=17)$; open circles, high-mFVIla N2 $(n=11)$. ${ }^{*} P<0.05$ versus WT.

we did not observe significant differences in platelet counts or TF levels (prepared from pulmonary and cardiac cell lysates) in the N1 and N2 mice (data not shown). Moreover, we did not observe any significant differences in TAT levels, clotting times (PT), or mFVIIa levels (data not shown).

Premature mortality in high FVIIa-expressing mice is associated with pathologic findings in heart and lungs. To investigate the causes of premature mortality, we carried out histopathologic studies of high FVIIa expressers on both normal and HB backgrounds. Results were identical for normal and hemophilic background in high-mFVIIa transgenic mice sacrificed or expiring at time points ranging from 2 to 6 months of age. Necropsy revealed no gross abnormalities. Histopathologic analyses of brain, liver, and kidney were also normal. Major pathologic findings were confined to the lungs and heart (Figure 5). The lungs of 4 of 8 mice examined showed increased fibrin deposition and intimal/smooth muscle proliferation in the pulmonary vasculature. In the hearts of all 8 mice examined, even in these relatively young mice aged less than 6 months, thrombi were present in coronary vessels and in the chambers of the heart. Occasional patchy inflammatory cell infiltrates were also noted. Immunohistochemical staining for fibrin showed increased fibrin deposition in the myocardium in a multifocal pattern. As a follow-up to these observations, we sacrificed 6 low-mFVIIa transgenic mice on a normal background at 18 months of age to search for evidence of pathologic findings in heart or lungs, but these tissues appeared normal even in these older low-mFVIIa transgenic mice (data not shown). None of these findings were observed in the 10 age-matched nontransgenic controls examined ( $P=0.02$ in lungs; $P<0.0001$ in heart) or in the 6 low-mFVIIa transgenic mice examined up to 18 months of age ( $P=0.085$ in lungs; $P<0.0001$ in heart).
Crossing to low-FX mice restores normal survival. Although the mechanism of action of high-dose FVIIa is still controversial, the end product is the generation of FXa. In an effort to rescue the high-expressing mFVIIa transgenic mice, which had repeatedly succumbed at early time points, and to determine whether the premature mortality was mediated through FXa generation, we crossed these mice to mice with low levels of mFX activity. These mice are F10 knockouts and knockins for a $F 10$ variant based on a human FX (hFX) mutation (FX ${ }^{\text {Friuli; }}$; ref. 10$)$ that results in low FX activity $(-5.5 \%)$ in homozygous mice without affecting survival (6). The targeted knockin of the murine $F 10^{\text {Friuli }}$ allele $\left(F 10^{\mathrm{tm} 2 \mathrm{Ccmt}}\right)$ allows expression of this variant from the endogenous promoter. To determine whether low mFX activity rescued the early mortality seen in mice overexpressing mFVIIa, we crossed these 2 mouse lines and analyzed littermates with high mFVIIa levels and low, mid-range, or normal $\mathrm{mFX}$ activity (about 3\%, 50\%, and $100 \%$, respectively; Figure 6). The low-mFX mice were on a predominantly C57BL/6 background (backcrossed for 5 generations). Coagulation assays showed comparable levels of mFVIIa in all 3 groups as measured by ELISA (Figure 6A). As expected, mice with low mFX activity had prolonged PT compared with mice with mid-range or WT mFX activity (Figure 6B). TAT levels also varied among the 3 groups of mice, with markedly elevated levels in mFVIIa transgenic mice with $100 \% \mathrm{mFX}$ activity, lower but still elevated levels in mice with $50 \% \mathrm{mFX}$ activity, and levels close to those of nontransgenic WT littermates in mice with $3 \% \mathrm{mFX}$ activity (Figure 6C). The consequences of these altered coagulation parameters are clear in the survival curves for these animals. Among mice expressing high levels of mFVIIa, survival at 11 months was $0 \%$ for mice with WT mFX activity (F1 and F2, $P<0.0001$ versus $\mathrm{WT}), 18 \%$ for mice with $50 \% \mathrm{mFX}$ activity $(P<0.0001$ versus WT), and $100 \%$ for mice with $3 \% \mathrm{mFX}$ activity (Figure 6D). Histologic analysis of tissues from 4 high-mFVIIa mice with either $100 \%$ or $50 \% \mathrm{mFX}$ showed thrombi similar in distribution to those found in high-mFVIIa mice crossed to hemostatically normal mice (Figure 5 and data not shown).

\section{Discussion}

The development of rhFVIIa to effect hemostasis in hemophilic patients with inhibitors was a major advance in the management of what is currently the most common complication of treatment for hemophilia. However, the short half-life and substantial expense of the product remain impediments to more extensive use in the setting of hemophilia. Gene transfer offers the possibility of circumventing the short half-life, because expression from the donated gene is continuous. In addition, as a gene therapy product, FVIIa has the advantage that all hemophilic subjects are fully tolerant to it. Ongoing advances in AAV-mediated gene transfer suggest that successful clinical application will occur for other clotting factors $(11,12)$. We undertook the studies here in an attempt to define safe and efficacious levels of FVIIa in the setting of continuous expression.

The present study reports 2 major findings: first, that continuously expressed FVIIa demonstrates safety and hemostatic efficacy over a fairly broad range of levels and over the lifespan of the mouse, and second, that high-level continuous expression of FVIIa is associated with early mortality, by a mechanism dependent on FX. Previously, we showed that AAV-mediated gene transfer of an engineered FVIIa construct to the liver resulted 

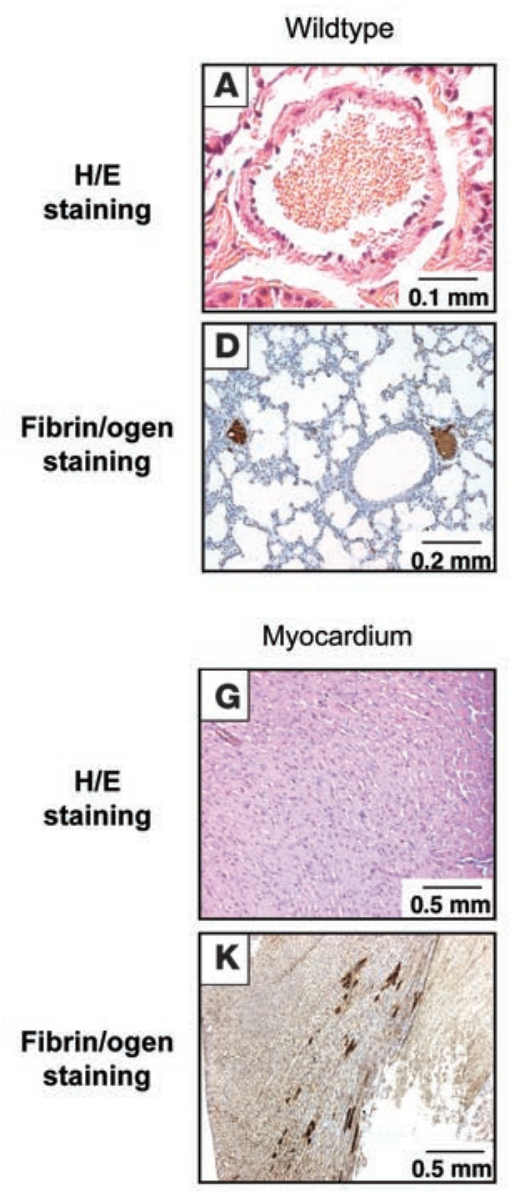

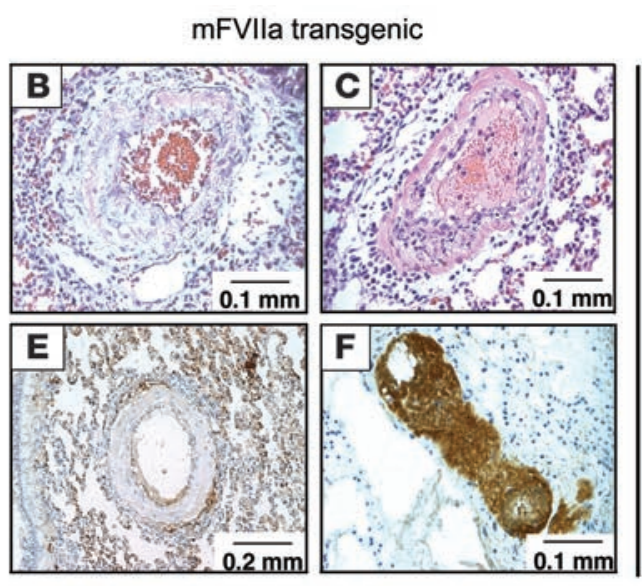

Lung

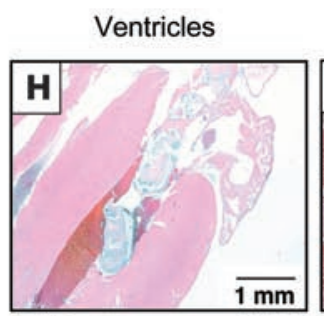

Coronary artery
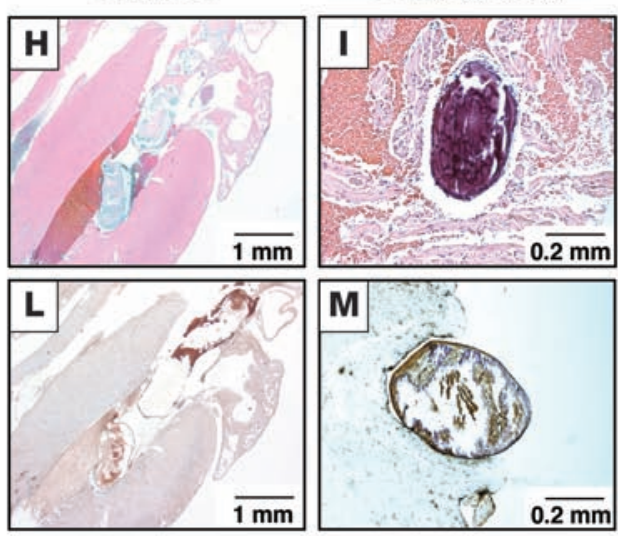

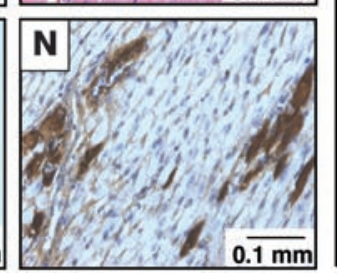

Heart

Myocardium

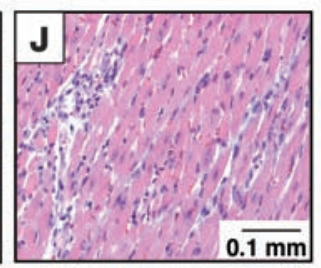

Heart

\section{Figure 5}

Histological findings in lungs and hearts of high-mFVIla transgenic mice compared with WT littermates. Intimal/smooth muscle proliferation was observed in the pulmonary veins (B and $\mathbf{C}$ ) as well as fibrin deposition in the pulmonary bed (E and $\mathbf{F}$ ) of mFVIla transgenic mice, but neither was seen in WT mice (A and $\mathbf{D})$. Thrombi were observed in the coronary artery $(\mathbf{I}$ and $\mathbf{M})$ and ventricles $(\mathbf{H}$ and $\mathbf{L})$ as well as inflammatory infiltrates in the myocardium ( $\mathbf{J}$ and $\mathbf{N}$ ) of $\mathrm{mFVIla}$ transgenic mice, but none were observed in WT mice $(\mathbf{G}$ and $\mathbf{K})$. Original magnification, $\times 20(\mathbf{H}$ and $\mathbf{L})$; $\times 40(\mathbf{G}$ and $\mathbf{K}) ; \times 100(\mathbf{D}, \mathbf{E}, \mathbf{I}$, and $\mathbf{M}) ; \times 200(\mathbf{A}-\mathbf{C}, \mathbf{F}, \mathbf{J}$, and N).

in continuous expression of FVIIa and that hemophilic mice expressing mFVIIa for periods up to 6 months exhibited correction of plasma-based coagulation assays (PT and aPTT) and partial correction of the tail-clip bleeding time after vector infusion (5). We demonstrate that circulating levels of mFVIIa in the range of $500-1,500 \mathrm{ng} / \mathrm{ml}(10-30 \mathrm{nM})$ in hemophilic mice shorten the PT, correct the aPTT to the normal range, and modestly increase TAT levels. The levels seen in the low-mFVIIa transgenic mice closely approximated the levels obtained from AAV-mediated transduction, as seen in our previous study (5) and in data presented here (Table 2). These levels are similar to the peak therapeutic levels seen in patients infused with recombinant FVIIa (10-20 nM; ref. 13). Moreover, these mice exhibited a normal lifespan through the 16 -month study duration, similar to AAV-treated mice (Table 2), and at necropsy showed no unusual pathology. In terms of efficacy, in vivo tests of coagulation provide a more nuanced view of mFVIIa-supported hemostasis in hemophilic mice than do standard plasma-based assays. Clot formation in the microvasculature, as measured in the cremaster arterioles after a laser injury, appeared indistinguishable from that seen in WT mice, and blood loss on the tail-clip assay was reduced compared with hemophilic nontransgenic littermates, although not to the levels seen in WT littermates. On the other hand, in the $\mathrm{FeCl}_{3}$ injury model of the carotid artery (macrovasculature), there was no clot formation in the transgenic mice, even after a prolonged period of observation.

A possible explanation for these discordant findings of clot formation in the micro- and macrocirculation may be due to differences in multiple factors, including the size of the vessel and/or the mechanism of clot formation in these settings. Chou et al. showed that clot formation in the microcirculation relies primarily on circulating TF, e.g., from microparticles (14). Clot formation in large diameter vessels, on the other hand, depends on exposure of vessel wall (subendothelial) TF (15). Additionally, the difference seen in the 3 injury models used here may be a reflection of the type of injury. For example, thrombus formation in the $\mathrm{FeCl}_{3}$ model appears to rely primarily on the glycoprotein VI-collagen pathway (16), whereas in the laser-induced injury model, initial thrombus formation relies on the TF-mediated pathway of thrombin generation (17). Finally, although we do not have direct evidence, we cannot exclude the possibility that continuous expression results in an increased extravascular pool of mFVIIa 
A
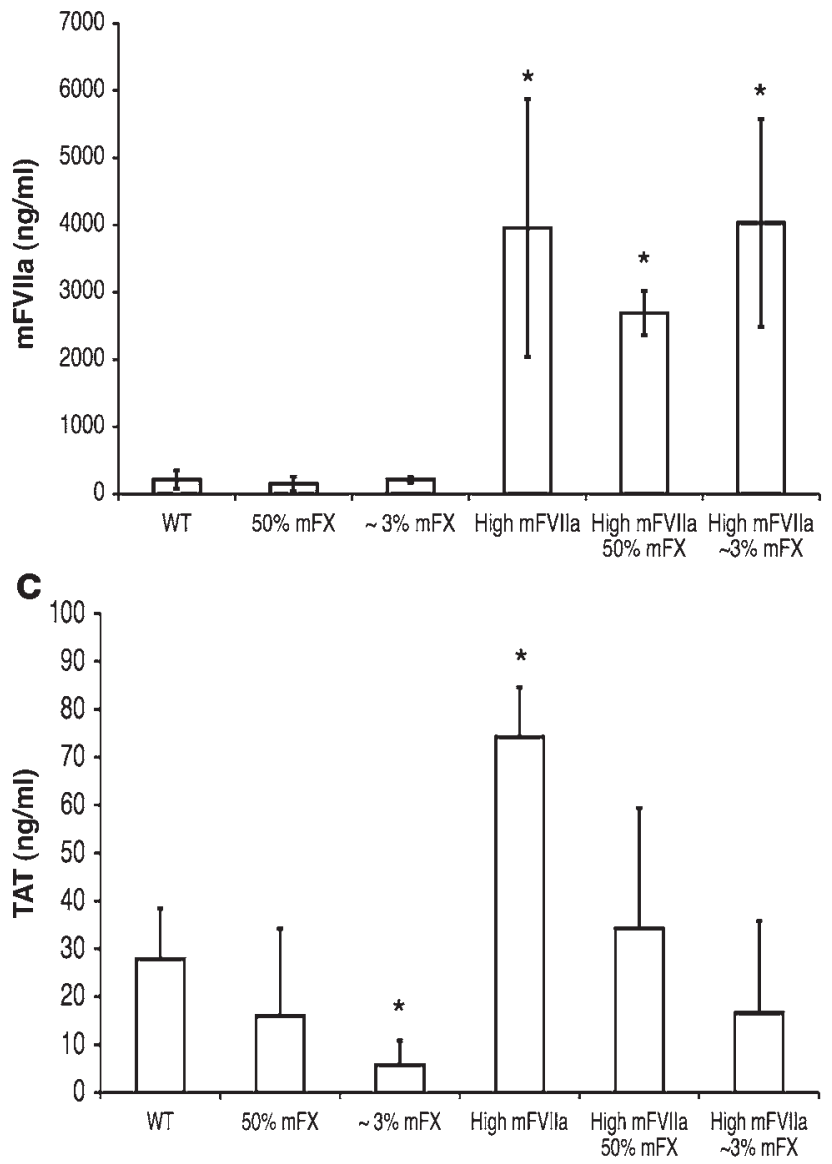

B
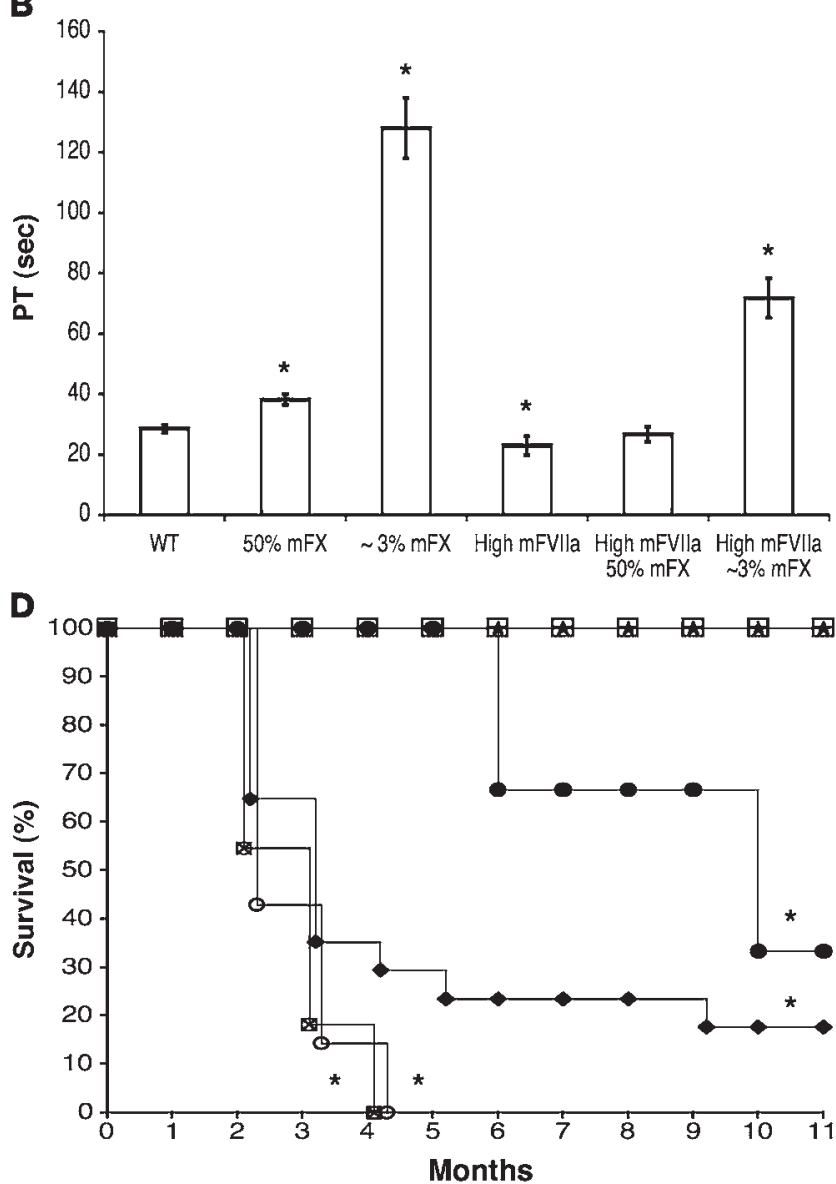

Figure 6

Hemostatic differences in high-mFVIla transgenic mice. (A) mFVIla antigen; (B) PT measurements using hFX-deficient plasma; (C) TAT levels; and (D) Kaplan-Meier survival plot of high-mFVlla transgenic mice in a background between $\sim 3 \%$ and $100 \% \mathrm{mFX}$. (A-C) $n=3(\sim 3 \% \mathrm{mFX}$ and high-mFVIla $\sim 3 \% \mathrm{mFX}$ ), 4 (high-mFVIla), 6 (WT), 8 (50\% mFX), 12 (high-mFVIla 50\% mFX). (D) Open squares, WT ( $n=10)$; filled circles, highmFVIla F0 ( $n=3)$; stars, high-mFVIla F2 $2 \%$ mFX $(n=8)$; diamonds, high-mFVIla F2 50\% mFX ( $n=17)$; crossed-out squares, high-mFVIla F1 $100 \% \mathrm{mFX}(n=11)$; open circles, high-mFVIla F2 100\% $\mathrm{mFX}(n=7) .{ }^{*} P<0.05$ versus WT. Values are mean \pm 1 SD.

that may affect, or at least facilitate, the differences seen in the in vivo injury models described here. Elevated levels of extravascular FVIIa have been proposed as the explanation for the reduced number of bleeds observed in hemophilic patients undergoing daily infusions of rhFVIIa, both during and for 3 months after the infusions $(18,19)$. Additionally, hFVIIa activity of $34 \%$ has been reported in human lymph fluid that bathes the extravascular space (20). More pertinent to this study, the presence of mFVIIa has previously been demonstrated in the perivascular space outside dermal vessels even in the absence of tissue damage (21).

A critical question is the relationship of these findings to the frequency of bleeding in patients with hemophilia. The major morbidity of hemophilia stems from repeated bleeds into the joints that result in synovial hypertrophy, intense neovascularization, and inflammation (22). If indeed most of these bleeds begin as unsealed nicks in the microcirculation, then a normalized response to a hemostatic challenge in the microcirculation, as continuously expressed FVIIa seems to provide, could conceivably result in a reduced number of joint bleeds. A caveat in extrapolating these findings to humans is that mice generally have platelet counts 3- to 4-fold higher than do humans (23), which may result in a better outcome in this model, although the murine mean platelet volume is also smaller (one-half that of human platelets; refs. 24, 25), which compensates for the increased count. If, as has been proposed, most of the bloodborne TF comes from leukocyte-derived microparticles (14), the difference in platelet counts may be of limited concern in interpretation of results. The effect of continuously expressed FVIIa on frequency of joint bleeds will perhaps be better assessed in a canine model of hemophilia, where observation of animals over many years has established a baseline number of readily diagnosed bleeds, including joint bleeds, in untreated animals (26). Improvement of hemostasis in a large-animal model has previously been a strong predictor of efficacy of products in human subjects (27-29).

In addition to defining a range at which continuously expressed FVIIa appears to be safe and improves hemostasis, the other major finding in this study is the early mortality associated with high-level continuous expression of FVIIa. Although mice expressing lower levels of FVIIa exhibited normal lifespan and 
absence of pathology (100\% of mice alive and free of pathologic changes at 16 months), those expressing FVIIa in the range of $3,000 \mathrm{ng} / \mathrm{ml}$ showed early mortality, with $50 \%$ of founder mice surviving at 16 months. Several lines of evidence suggest that increased thrombin generation and resultant pathologic thrombus formation account for this finding. The most direct evidence comes from histopathologic studies of the high-FVIIa mice, which exhibited pathologic thrombi and increased fibrin deposition even at young ages. These findings are reminiscent of those described by Ameri et al. in mice transgenic for hFIX, although those animals exhibited altered histopathology and premature mortality with modest increases in FIX levels (30), whereas in our study continuous expression of mFVIIa appeared safe over a broad range of lower levels. Our finding of pathology primarily in the heart and lungs is consistent with the high levels of TF in these organs $(31,32)$ and supports the concept of TF forming a hemostatic envelope that affords additional hemostatic protection against repetitive mechanical injury for the vasculature of the heart and lungs (33). This observation also demonstrates the power of the transgenic approach used here that afforded extremely high levels of mFVIIa expression. We were not able to attain circulating levels this high using AAV vectors; in practice this may constitute an unexpected safety feature of AAV2-mediated FVIIa expression.

Consistent with the histologic findings, other evidence suggesting increased thrombin generation as the cause of the premature mortality includes the elevated TAT levels in the high expressers and rescue of the high expressers by crossing to low-mFX mice. The normalization of the TAT levels in the high expressers after crossing to the low-mFX mice and the restoration of survival despite being crossed to a predominantly C57BL/ 6 background lends further support to thrombin generation as the etiology of the early mortality. However, we cannot exclude a role for other genetic factors. The moderate TAT levels in the low expressers, although statistically different from those in WT mice, suggest thrombin levels that are well-tolerated in the organism, while the more marked increase in the high expressers does not suggest this (Figure 2D and Figure 4).

As was the case for the efficacy findings in the murine model (vide supra), the issue for the findings of increased mortality is how they relate to the risk of increased thrombin generation in humans continuously expressing FVIIa (i.e., after gene transfer). There has been ongoing controversy about the risk of thromboembolic events in individuals receiving bolus infusions of rhFVIIa $(4,34)$. Initial experience with rhFVIIa, mostly in the hemophilia population, established that the risk of myocardial infarction, deep venous thrombosis, and cerebrovascular accidents as a consequence of rhFVIIa infusion was low, less than $1 \%$ in retrospective studies, and occurred mostly in older patients with predisposing conditions (34). Conversely, a recent prospective study of 399 patients with stroke caused by intracerebral hemorrhage who received either rhFVIIa or placebo showed a significant increase in arterial thromboembolic events, mainly myocardial or cerebral infarction, in the FVIIa-treated group, although overall this group showed increased survival and less disability compared with the placebo group (35). Clearly, the patients in the cerebral hemorrhage group were older and had predisposing factors for thrombosis compared with the hemophilia patients initially studied. Nevertheless, although our model relies on continuous expression of FVIIa in contrast to bolus infusion, our data are consistent with the finding that thromboembolic events are indeed a potential consequence of elevated FVIIa levels.

In summary, we have established that continuous expression of activated FVII is safe over a range of levels in a mouse model of hemophilia (300-1,500 ng/ml, or 6-30 nM) and that these levels improve hemostasis as judged by in vitro clotting assays and by hemostatic response to a laser injury in the microcirculation. Although a direct comparison between mice and humans is difficult due to the differences in the mode of administration (bolus infusion versus continuous), these levels of expression fall within the clinically defined therapeutic range (10-20 nM peak) and can be achieved by AAV-mediated gene transfer. However, we also show early mortality, characterized by thrombus formation and fibrin deposition in lungs and heart, as a complication of continuous expression at levels greater than $2,000 \mathrm{ng} / \mathrm{ml}$ (40 nM). This early mortality was rescued by crossing to mice with low circulating levels of FX. Our data suggest that the margin between the lowest effective dose $(6 \mathrm{nM})$ and the highest safe dose $(30 \mathrm{nM})$ is narrow, but this is characteristic of a number of drugs that alter coagulation.

Enabled by continuing advances in systems biology and by the ability to transfer any gene of interest, novel therapeutic approaches to genetic disorders based on transfer of genes other than those affected by mutations will continue to be explored $(36,37)$. Based on the FVIIa model, it will be crucial to carefully define the boundaries of safety and efficacy over prolonged periods of time and to scrutinize the effect of continuous transgene expression on disease pathophysiology.

\section{Methods}

Generation of FVIIa and FVII transgenic mice. The 2.3-kb fragment containing the mFVII-2RKR transgene (mFVIIa, containing the full mFVII untranslated region) with a synthetic intron from the AAV-hAATmFVIIa (5) was partially digested and purified with SacII and XbaI. A $K p n I$ linker fragment containing SacII and $X b a I$ sites was ligated to a KpnI-digested plasmid containing the liver-specific mTTR promoter (38) driving expression of hFIX (pTTR-hFIX; ref. 8). The intron-mFVIIa fragment was ligated to the PTTR vector. To generate pTTR-mFVII (zymogen), pTTR-mFVIIa and pAAV-hAAT-mFVII (containing the full mFVII untranslated region) were partially digested with $\mathrm{ClaI} / \mathrm{XbaI}$ to release mFVIIa and mFVII, respectively, and the ClaI/XbaI mFVII fragment was ligated into digested $\mathrm{pTTR}$ vector. Sequencing was performed to confirm the presence or absence of the $2 \mathrm{RKR}$ sequence in $\mathrm{mFVII}$ cDNA. Purified plasmid preparations were generated for each construct by standard cesium chloride gradient purification. The fragments for microinjection were released by HindIII restriction enzyme digestion, isolated by agarose gel electrophoresis, recovered by ethanol precipitation, and purified with an Elutip-d minicolumn (Sigma-Aldrich) according to the manufacturer's instructions. DNA fragments were dissolved in injection buffer (10 mM Tris and $0.1 \mathrm{mM}$ EDTA, $\mathrm{pH} 7.5)$ and adjusted to the appropriate concentration. DNA was injected into a minimum of 150 fertilized eggs at a concentration of $5 \mathrm{ng} / \mu \mathrm{l}$ using standard microinjection techniques (Transgenic and Chimeric Mouse Facility, University of Pennsylvania) (39). Genomic DNA was extracted from tail biopsies or blood using tissue and blood DNA extraction kits (Qiagen). Transgenic pups were identified by a TTR-specific forward primer $\left(5^{\prime}\right.$ GGCAGGGATCAGCAGCCTGG-3') and a cDNA-specific reverse primer (5'-CCCCACATTCCTCTTCCTCCTCTTCCTTCGGCCTTGG-3'), with a PCR program of $95^{\circ} \mathrm{C}$ for $2 \mathrm{~min}, 30$ cycles of $94^{\circ} \mathrm{C}$ for $30 \mathrm{~s}, 62^{\circ} \mathrm{C}$ for $1 \mathrm{~min}$, and $72^{\circ} \mathrm{C}$ for $1.5 \mathrm{~min}$, and a final extension at $72^{\circ} \mathrm{C}$ for $20 \mathrm{~min}$. 
Experimental animals and $A A V$ administration. All procedures and animal care were approved by the IACUC at the Children's Hospital of Philadelphia. The transgenic founders were hybrid $\mathrm{F} 1$ generation resulting from a cross between C57BL/ 6 and SJL mice (The Jackson Laboratory). Transgenic mice were further backcrossed to pure C57BL/6 mice, resulting in early mortality (vide infra); thus all studies were conducted in F0 and N1-N4 mice, using nontransgenic congenic littermates as controls. Murine platelet counts were determined as previously described (40). AAV vector was prepared as previously described (5) and administered via the portal vein as previously described (41).

Tail-clip assay (severe bleeding model). For tail-clip assays, tails were prewarmed at $37^{\circ} \mathrm{C}$ for $2 \mathrm{~min}$ and then cut at a diameter of $3 \mathrm{~mm}$ and immersed in prewarmed saline. Time to cessation of bleeding was recorded if less than $10 \mathrm{~min}$; otherwise, the experiment was terminated at $10 \mathrm{~min}$ and the tail cauterized to stop bleeding. The blood-containing saline was centrifuged at $520 \mathrm{~g}$ for $10 \mathrm{~min}$ at $4^{\circ} \mathrm{C}$. Subsequently, $6 \mathrm{ml}$ lysis buffer $\left(10 \mathrm{mM} \mathrm{KHCO}_{3}, 150 \mathrm{mM} \mathrm{NH}_{4} \mathrm{Cl}\right.$, and $1 \mathrm{mM} \mathrm{EDTA}$ ) was added to the red blood cell pellet, and the lysis proceeded for $10 \mathrm{~min}$ at room temperature, after which the samples were centrifuged as described above and $O D_{575} \mathrm{~nm}$ of the supernatants was measured. For all assays, nontransgenic littermates served as controls.

$\mathrm{FeCl}_{3}$ carotid artery model. The carotid arteries of adult mice were exposed, a Doppler flow probe (model 0.5VB; Transonic Machinery Systems) was placed on the surface of the exposed artery, and a baseline blood flow measurement was recorded. Subsequently, a $2 \mathrm{~mm}^{2}$ piece of Whatman No. 1 paper soaked in a $15 \%$ solution of $\mathrm{FeCl}_{3}$ was applied to the adventitial surface of the exposed artery for $2 \mathrm{~min}$, after which it was removed and carotid artery blood flow was recorded. Time to carotid artery occlusion was defined as the time from initiation of arterial injury until the onset of stable occlusion (42).

Real-time wide-field intravital microscopy. The cremaster muscles of adult mice were exposed, stretched, and pinned across the intravital microscopy tray. The rat anti-CD41 (murine platelet glycoprotein complex IIb/IIIa) Alexa Fluor 555-labeled antibody (Invitrogen) was infused at a dose of 10 $\mathrm{mg} /$ mouse. Immediately after infusion of the antibody, a laser-induced injury was performed on the vessel wall of the cremasteric arterioles (9). The injuries were performed using a pulse-nitrogen dye laser applied through the micropoint laser system (Photonic Instruments). We used an Olympus BX6IWI fixed-stage motorized upright fluorescence microscope with a long-distance condenser and $\times 40$ water-immersion objective. Data analysis was carried out using Slidebook 4.0 software (Intelligent Imaging Innovations). Fluorescence data were captured digitally for up to $10 \mathrm{~ms}$ per event for 300 frames. The amount of platelet accumulation in the developing thrombi was determined as the sum of all pixel values of the plateletspecific signal and expressed as relative fluorescent units, an arbitrary unit in which the integrated platelet fluorescence intensity is reflected.

Protein expression and purification, antibody production, and development of ELISAs. mFVIIa was purified, and polyclonal antibodies against purified mFVIIa were raised in rabbits as previously described (5). A fraction of the antibody was labeled with HRP according to the manufacturer's instructions (Roche). Total mFVII/mFVIIa protein was measured by a sandwich ELISA using purified mFVII protein as a standard and the rabbit antimFVII as capture and detecting (HRP-labeled) antibody. To measure the levels of mFVIIa in mouse plasma, we developed a second ELISA with minimal cross-reactivity to mFVII zymogen. Briefly, diluted murine plasmas were first incubated with an excess of a biotinylated active site probe D-phenylalanyl-L-prolyl-L-arginine chloromethyl ketone (Haematologic Technologies) for $30 \mathrm{~min}$ at $4^{\circ} \mathrm{C}$, after which the mixture was loaded onto a plate precoated with the rabbit anti-mFVII antibody and incubated at $4^{\circ} \mathrm{C}$ for 1 hour. The bound fraction of the biotinylated inhibitor was detected after a 30-min incubation at room temperature with HRP-streptavidin (BD Biosciences - Pharmingen). $\mathrm{OD}_{450 \mathrm{~nm}}$ was measured, and protein concentrations were calculated against a standard curve constructed from serial dilutions of purified mFVIIa protein. As a third method, mFVIIa levels were extrapolated from a standard curve generated by spiking known amounts of purified mFVIIa into normal mouse plasma followed by clotting assay. PTs from diluted plasma samples were plotted, and mFVIIa levels were estimated against the standard curve. Levels of mFVIIa expression determined by PT standard curve and inhibitor-based ELISA were in excellent agreement $(r>0.93)$, whereas the total antigen ELISA reported higher total antigen as a result of endogenous mFVII present in mouse plasma samples or mFVIIa complexed with serpins. TF levels were assayed in cell lysates from pulmonary and cardiac C57BL/6 or SJL tissues by Western blotting using primary antibodies raised in 2 different species, i.e., goat anti-mTF (Santa Cruz Biotechnologies Inc.) and sheep anti-hTF (Haematologic Technologies) (43).

TAT and clotting assays. All reagents were prewarmed to $37^{\circ} \mathrm{C}$ before use. Mouse plasma for clotting assays was collected into one-tenth volume of $3.8 \%$ sodium citrate solution from the tail following a small snip. The first drop was discarded. PTs were measured by adding $50 \mu 1$ citrated mouse plasma diluted 1:40 to $50 \mu \mathrm{l} \mathrm{hFVII-} \mathrm{or} \mathrm{hFX-deficient} \mathrm{plasma} \mathrm{(bioMérieux),}$ and the time to clot formation was recorded with a fibrometer (BBL Fibrosystem; Becton Dickinson) after adding $200 \mu \mathrm{l} \mathrm{rhTF}$ with calcium (Innovin; Dade Behring). aPTTs were measured by adding $50 \mu \mathrm{l}$ undiluted citrated mouse plasma to $50 \mu \mathrm{l} \mathrm{hFIX-deficient} \mathrm{plasma} \mathrm{(bioMérieux)} \mathrm{and} 50 \mu \mathrm{laPTT}$ reagent (bioMérieux). The mix was incubated at $37^{\circ} \mathrm{C}$ for $3 \mathrm{~min}$ before $50 \mu \mathrm{l}$ of $25 \mathrm{mM} \mathrm{CaCl}_{2}$ was added, and time to clotting was recorded with a fibrometer. The TAT complex assay was performed on citrated mouse plasma using the Enzygnost TAT micro kit (Dade Behring) following the manufacturer's protocol. Rotational thromboelastometry was performed using citrated whole blood, as previously described (44).

Histology and immunohistochemistry. Tissues obtained at necropsy were fixed in $10 \%$ formalin and paraffin embedded according to standard protocols. Tissues were sectioned and stained with H\&E. In addition, immunohistochemistry was performed using fibrin/fibrinogen polyclonal antibody (Dako) following the manufacturer's protocol.

Statistics. A 2-tailed Student's $t$ test was used for statistical analysis. Kaplan-Meier plots and analysis were performed using the JMP 6.0 software package (SAS Institute). Statistical analysis on the pathology findings was performed using Fisher's exact test. A $P$ value less than 0.05 was considered significant.

\section{Acknowledgments}

The authors wish to thank Daniel Martinez at the Children's Hospital of Philadelphia Pathology Core facility as well as Valder R. Arruda for his helpful comments and discussions. K.A. High was supported by the Howard Hughes Medical Institute and by NIH grants U01 HL66948 and P01 HL074124.

Received for publication June 1, 2007, and accepted in revised form February 15, 2008.

Address correspondence to: Katherine A. High, Howard Hughes Medical Institute, The Children's Hospital of Philadelphia, 3615 Civic Center Blvd., 302 Abramson Research Center, Philadelphia, Pennsylvania 19104, USA. Phone: (215) 590-4521; Fax: (215) 590-3660; E-mail: high@email.chop.edu.

Majed N. Aljamali's present address is: Novo Nordisk A/S, Måløv, Denmark. 
1. Hedner, U., and Ingerslev, J. 1998. Clinical use of recombinant FVIIa (rFVIIa). Transfus. Sci. 19: $163-176$

2. Ingerslev, J., et al. 1996. Major surgery in haemophilic patients with inhibitors using recombinant factor VIIa. Haemostasis. 26(Suppl. 1):118-123.

3. Shapiro, A.D. 2000. Recombinant factor VIIa in the treatment of bleeding in hemophilic children with inhibitors. Semin. Thromb. Hemost. 26:413-419.

4. O'Connell, K.A., Wood, J.J., Wise, R.P., Lozier, J.N., and Braun, M.M. 2006. Thromboembolic adverse events after use of recombinant human coagulation factor VIIa. JAMA. 295:293-298.

5. Margaritis, P., et al. 2004. Novel therapeutic approach for hemophilia using gene delivery of an engineered secreted activated Factor VII. J. Clin. Invest. 113:1025-1031.

6. Tai, S.J., et al. 2007. A viable mouse model for Factor $\mathrm{X}$ deficiency provides evidence for maternal transfer of Factor X. J. Thromb. Haemost. 6:339-345.

7. Idusogie, E., et al. 1996. Characterization of a cDNA encoding murine coagulation factor VII. Thromb. Haemost. 75:481-487.

8. Sabatino, D.E., et al. 2004. Novel hemophilia B mouse models exhibiting a range of mutations in the Factor IX gene. Blood. 104:2767-2774.

9. Falati, S., Gross, P., Merrill-Skoloff, G., Furie, B.C., and Furie, B. 2002. Real-time in vivo imaging of platelets, tissue factor and fibrin during arterial thrombus formation in the mouse. Nat. Med. 8:1175-1181.

10. James, H.L., Girolami, A., and Fair, D.S. 1991. Molecular defect in coagulation factor X Friuli results from a substitution of serine for proline at position 343. Blood. 77:317-323.

11. Manno, C.S., et al. 2006. Successful transduction of liver in hemophilia by AAV-Factor IX and limitations imposed by the host immune response. Nat. Med. 12:342-347.

12. Nathwani, A.C., et al. 2007. Safe and efficient transduction of the liver after peripheral vein infusion of self-complementary AAV vector results in stable therapeutic expression of human FIX in nonhuman primates. Blood. 109:1414-1421.

13. Villar, A., et al. 2004. Pharmacokinetics of activated recombinant coagulation factor VII (NovoSeven) in children vs. adults with haemophilia A. Haemophilia. 10:352-359.

14. Chou, J., et al. 2004. Hematopoietic cell-derived microparticle tissue factor contributes to fibrin formation during thrombus propagation. Blood. 104:3190-3197.

15. Day, S.M., et al. 2005. Macrovascular thrombosis is driven by tissue factor derived primarily from the blood vessel wall. Blood. 105:192-198.

16. Dubois, C., Panicot-Dubois, L., Merrill-Skoloff, G., Furie, B., and Furie, B.C. 2006. Glycoprotein VIdependent and -independent pathways of thrombus formation in vivo. Blood. 107:3902-3906.

17. Dubois, C., Panicot-Dubois, L., Gainor, J.F., Furie, B.C., and Furie, B. 2007. Thrombin-initiated platelet activation in vivo is vWF independent during thrombus formation in a laser injury model. J. Clin. Invest. 117:953-960.

18. Hedner, U. 2006. Potential role of rFVIIa in prophylaxis in severe haemophilia patients with inhibitors. J. Thromb. Haemost. 4:2498-2500.

19. Konkle, B., Friedrich, U., and Abrams, Z. 2006. Secondary prophylactic treatment with rFVIIa in patients with haemophilia A or B and inhibitors with high requirements for on-demand treatment [abstract]. Haemophilia. 12:363.

20. Miller, G.J., et al. 2000. Haemostatic factors in human peripheral afferent lymph. Thromb. Haemost. 83:427-432.

21. Hoffman, M., et al. 2007. Tissue factor around dermal vessels has bound factor VII in the absence of injury. J. Thromb. Haemost. 5:1403-1408.

22. Dunn, A.L. 2005. Management and prevention of recurrent hemarthrosis in patients with hemophilia. Curr. Opin. Hematol. 12:390-394.

23. Peters, L.L., et al. 2005. Quantitative trait loci for baseline white blood cell count, platelet count, and mean platelet volume. Mamm. Genome. 16:749-763.

24. Sachs, U.J., and Nieswandt, B. 2007. In vivo thrombus formation in murine models. Circ Res 100:979-991.

25. Ware, J. 2004. Dysfunctional platelet membrane receptors: from humans to mice. Thromb. Haemost. 92:478-485.

26. Russell, K.E., et al. 2003. Reduced bleeding events with subcutaneous administration of recombinan human factor IX in immune-tolerant hemophilia B dogs. Blood. 102:4393-4398.

27. Brinkhous, K.M., Hedner, U., Garris, J.B., Diness, V., and Read, M.S. 1989. Effect of recombinant factor VIIa on the hemostatic defect in dogs with hemophilia A, hemophilia B, and von Willebrand disease. Proc. Natl. Acad. Sci. U. S. A. 86:1382-1386.

28. Brinkhous, K.M., et al. 1985. Purified human factor VIII procoagulant protein: comparative hemostatic response after infusions into hemophilic and von Willebrand disease dogs. Proc. Natl. Acad. Sci. U. S. A. 82:8752-8756

29. Brinkhous, K.M., et al. 1996. Recombinant human factor IX: replacement therapy, prophylaxis, and pharmacokinetics in canine hemophilia B. Blood. 88:2603-2610.

30. Ameri, A., Kurachi, S., Sueishi, K., Kuwahara, M., and Kurachi, K. 2003. Myocardial fibrosis in mice with overexpression of human blood coagulation factor IX. Blood. 101:1871-1873.

31. Drake, T.A., Morrissey, J.H., and Edgington, T.S. 1989. Selective cellular expression of tissue factor in human tissues. Implications for disorders of hemostasis and thrombosis. Am. J. Pathol. 134:1087-1097.

32. Fleck, R.A., Rao, L.V., Rapaport, S.I., and Varki, N. 1990. Localization of human tissue factor antigen by immunostaining with monospecific, polyclonal anti-human tissue factor antibody. Thromb. Res. 59:421-437.

33. Mackman, N. 2005. Tissue-specific hemostasis in mice. Arterioscler. Thromb. Vasc. Biol. 25:2273-2281.

34. Roberts, H.R., Monroe, D.M., 3rd, and Hoffman, M. 2004. Safety profile of recombinant factor VIIa. Semin. Hematol. 41:101-108.

35. Mayer, S.A., et al. 2005. Recombinant activated factor VII for acute intracerebral hemorrhage. N. Engl. J. Med. 352:777-785.

36. Deconinck, N., et al. 1997. Expression of truncated utrophin leads to major functional improvements in dystrophin-deficient muscles of mice. Nat. Med. 3:1216-1221.

37. Nelson, R. 2004. Utrophin therapy for Duchenne muscular dystrophy? Lancet Neurol. 3:637.

38. Yan, C., Costa, R.H., Darnell, J.E., Jr., Chen, J.D., and Van Dyke, T.A. 1990. Distinct positive and negative elements control the limited hepatocyte and choroid plexus expression of transthyretin in transgenic mice. EMBO J. 9:869-878.

39. Hogan, B., et al. 1986. Manipulating the mouse embryo: a laboratory manual. Cold Spring Harbor Laboratory Press. Cold Spring Harbor, New York, USA. 332 pp.

40. Rauova, L., et al. 2006. Role of platelet surface PF4 antigenic complexes in heparin-induced thrombocytopenia pathogenesis: diagnostic and therapeutic implications. Blood. 107:2346-2353.

41. Nakai, H., et al. 1998. Adeno-associated viral vector-mediated gene transfer of human blood coagulation factor IX into mouse liver. Blood. 91:4600-4607.

42. Farrehi, P.M., Ozaki, C.K., Carmeliet, P., and Fay, W.P. 1998. Regulation of arterial thrombolysis by plasminogen activator inhibitor-1 in mice. Circulation. 97:1002-1008

43. Szotowski, B., et al. 2005. Alterations in myocardial tissue factor expression and cellular localization in dilated cardiomyopathy. J. Am. Coll. Cardiol. 45:1081-1089.

44. Callan, M.B., et al. 2006. A novel missense mutation responsible for factor VII deficiency in research Beagle colonies. J. Thromb. Haemost. 4:2616-2622. 